\title{
BMJ
}

\section{Frailty and type of death among older adults in China: prospective cohort study}

\author{
Matthew E Dupre, sociologist, ${ }^{1}$ Danan Gu, demographer, ${ }^{2}$ David F Warner, sociologist, ${ }^{3}$ Zeng Yi, \\ demographer ${ }^{4,5}$
}

${ }^{1}$ Department of Sociology and

Center for the Study of Aging and

Human Development, Duke

University Medical Center, Durham,

NC 27710, USA

${ }^{2}$ Urban Studies and Planning,

Portland State University, 506 SW

Mill Street 570M, Portland, OR

97207, USA

${ }^{3}$ Department of Sociology, Case Western Reserve University,

Cleveland, $\mathrm{OH}$

${ }^{4}$ Center for the Study of Aging and Human Development, Duke University Medical Center,

Durham, NC

${ }^{5}$ China Center for Economic Research, Peking University, Beijing, China

Correspondence to: M E Dupre med11@geri.duke.edu or D Gu gudanan@yahoo.com

Cite this as: BMJ 2009:338:b1175 doi:10.1136/bmi.b1175

\section{ABSTRACT}

Objective To examine the association between frailty and type of death among the world's largest oldest-old population in China.

Design Prospective cohort study.

Setting 2002 and 2005 waves of the Chinese longitudinal healthy longevity survey carried out in 22 provinces throughout China.

Participants 13717 older adults (aged $\geq 65$ ).

Main outcome measures Type of death, categorised as being bedridden for fewer than 30 days with or without suffering and being bedridden for 30 or more days with or without suffering.

Results Multinomial analyses showed that higher levels of frailty significantly increased the relative risk ratios of mortality for all types of death. Of those with the highest levels of frailty, men were most likely to experience 30 or more bedridden days with suffering before death (relative risk ratio $8.70,95 \%$ confidence interval 6.31 to 12.00 ) and women 30 or more bedridden days with no suffering $(11.53,17.84$ to 16.96$)$. Regardless of frailty, centenarians and nonagenarians were most likely to experience fewer than 30 bedridden days with no suffering, whereas those aged 65-79 and 80-89 were more likely to experience fewer than 30 bedridden days with suffering. Adjusting for compositional differences had little impact on the link between frailty and type of death for both sexes and age groups.

Conclusions The association between frailty and type of death differs by sex and age. Health scholars and clinical practitioners should consider age and sex differences in frailty to develop more effective measures to reduce preventable suffering before death.

\section{INTRODUCTION}

Human frailty is a universal feature of the ageing process that signals the progression and accumulation of physical, psychological, and social deficits in older adults. ${ }^{1-5}$ Evidence from clinical studies suggests that frailty is a valid and reliable proxy of biological age (as opposed to chronological age), which provides a robust measure of the balance between health assets and deficits across a variety of dimensions. ${ }^{3-12}$ Accordingly, there is increasing awareness that quantifying levels of frailty, termed a "frailty index," is important for identifying differences in ageing in a population and as a numerical tool for monitoring individual susceptibility to disease and death. ${ }^{11} 1{ }^{13}$ Empirical studies of frailty on a national level are, however, limited.

Health scholars and practitioners widely agree that promoting healthy longevity is accomplished with not only advances in age but through healthier survival and an improved quality of death. ${ }^{20-22}$ To date, research on the quality and type of death is primarily limited to cross sectional and non-representative studies in clinical settings. Drawing from this research, consensus is growing that the extent of suffering (pain and discomfort) and number of bedridden days are basic dimensions underlying the quality of death in late life. ${ }^{2023-28} \mathrm{In}$ the United States it is estimated that end of life care utilises nearly one eighth of all healthcare expenditures and about one third of Medicare expenditures. ${ }^{29}$ In developing countries such as China, however, most health care occurs at home-nearly $20 \%$ of the world's oldest old live in China and less than $2 \%$ of elderly people live in institutions. ${ }^{3031}$ The degree to which this increasingly frail population dies peacefully or experiences prolonged degeneration before death is unknown.

We carried out a prospective cohort analysis of the association between frailty and type of death among older adults ( $\geq 65$ years) in China. Using data from the 2002 and 2005 waves of the Chinese longitudinal healthy longevity survey, the largest nationally representative sample of older adults in China, we examined the impact of frailty on type of death among people aged 65 to 109 and investigated whether differences in mortality varied by sex and age.

\section{METHODS}

The Chinese longitudinal healthy longevity survey is a nationwide survey of one of the largest samples of people in the oldest-old age group ( $\geq 80$ years) in the world. Extensive questionnaires were used to collect information on personal characteristics, family and household characteristics, lifestyle and diet, psychological characteristics, economic resources, social support, and a myriad physical and cognitive health conditions. The survey began interviewing older adults with informed consent in 1998 from half of the counties and cities 


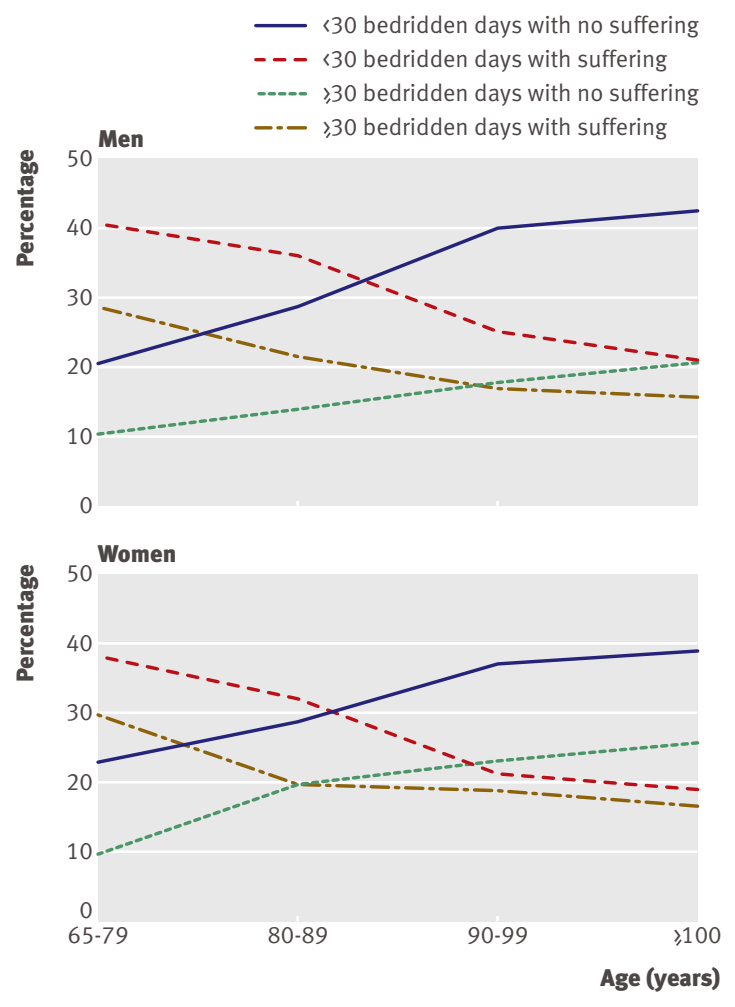

Fig 1| Observed proportion of type of death among deceased sample by age and sex in 2002 and 2005 waves of Chinese longitudinal healthy longevity survey

selected in 22 provinces in China. The major aim of the study was to collect a comparable sample of male and female octogenarians, nonagenarians, and centenarians. Follow-up interviews of the original sample and newly added samples-including adults aged 65 and older to replenish participants who had died or were lost to follow-up - were carried out in 2000, 2002, and 2005. The details of the sampling design, response rates, attrition, and systematic assessments of data quality across numerous measures in the survey are described elsewhere. ${ }^{32-34}$

The current analyses utilise data from the 2002 and 2005 waves of the survey. In the 2002 wave 15919 participants aged 65-109 were interviewed. The oversampling of older adults provided data on 4845 participants aged 65-79, 3747 nonagenarians, and 3088 centenarians. Of the 15919 interviewees in 2002, 8090 adults $(50.8 \%)$ were reinterviewed in 2005 and $5627(35.3 \%)$ died before follow-up in 2005 . The remaining 2202 adults (13.8\%) were lost to follow-up and were ultimately dropped from the present study, leaving an analytical sample of 13717 participants.

\section{Outcome measure}

As with most large scale studies, the Chinese longitudinal healthy longevity survey has limited qualitative measures to fully assess type of death. To overcome this shortcoming we integrated an objective indicator of physical failure with a subjective indicator of suffering before death to develop several categorisations of type of death between the 2002 and 2005 surveys. ${ }^{2325}$ Firstly, we dichotomised separate variables into participants who were bedridden for fewer than 30 days before death and those who were bedridden for 30 or more days before death. Testing other cut-off points for duration of being bedridden did not improve explanatory power.

Secondly, we dichotomised the subjective painfulness of death on the basis of an evaluation of the decedents' next of kin (peaceful $v$ non-peaceful) reported in the 2005 survey. Most elderly people in China reside in the community, ${ }^{31}$ which provides the unique opportunity for next of kin to report on the participant's suffering immediately before death. Although both measures were ascertained from next of kin, research shows that surrogate responses from family members and others are appropriate for obtaining reliable information on the health status and quality of death among older adults. ${ }^{3536}$

Finally, we grouped the two assessments of the participants' last month of life to categorise the deaths as follows: less than 30 bedridden days with suffering, less than 30 bedridden days with no suffering, 30 or more bedridden days with suffering, or 30 or more bedridden days with no suffering. The reference category in the multinomial regression models was survival over the three years.

\section{Frailty index and confounding risks}

Frailty is a physiological state of non-specific vulnerability to stressors resulting from decreased physiological reserves and the deregulation of multiple physiological systems associated with advancing age. ${ }^{1346-81037}$ Conceptually, frailty is not just an association with specific diseases or disabilities but rather a systemic manifestation of physical and cognitive deficits, including the signs, symptoms, illnesses, and impairments that accumulate over the life course. ${ }^{837}$

Empirically, a variety of methods have been used to quantify frailty, although the most common applications are the phenotypic approach and the frailty index. ${ }^{38}{ }^{39}$ The phenotypic approach defines frailty on the basis of several items, such as weight loss, exhaustion, weakness, slowness, or low physical activity, and considers any three conditions as an indication of frailty. ${ }^{5}$ Alternatively, a frailty index focuses less on the specific deficits of people and more on the cumulative number of health deficiencies. ${ }^{815}$ Despite the similarities between these approaches, the choice of measurement is often dictated by the clinical outcome under investigation. Accordingly, recent research shows that frailty indices are more applicable for studying mortality than are phenotypic methods. ${ }^{8389}$ In practice, most studies compute a frailty index as the proportion of cumulative health deficits to all possible deficits for a given individual. ${ }^{17}$

Following earlier research, we constructed a frailty index using 39 variables that included objective, subjective, and proxy reports of cognitive functioning, disability, auditory and visual ability, depression, heart rhythm, and numerous chronic diseases (details 
Table 1 |Characteristics of men in 2002 wave of Chinese longitudinal healthy longevity survey by level of frailty. Values are percentages of participants unless stated otherwise

\begin{tabular}{|c|c|c|c|c|c|c|}
\hline \multirow[b]{2}{*}{ Variables } & \multirow[b]{2}{*}{ Total } & \multicolumn{4}{|c|}{ Frailty index (fourths) } & \multirow[b]{2}{*}{$P$ value } \\
\hline & & 1st (least frail) & 2nd & $3 r d$ & 4th (most frail) & \\
\hline No of participants & 5904 & 1499 & 1561 & 1473 & 1371 & \\
\hline Survivors* & 61.9 & 84.9 & 75.1 & 56.6 & 28.7 & \multirow{6}{*}{$0 \dagger$} \\
\hline \multicolumn{6}{|l|}{ Type of death‡: } & \\
\hline $\begin{array}{l}\text { «30 bedridden days with no } \\
\text { suffering }\end{array}$ & 13.3 & 5.1 & 8.7 & 16.3 & 23.6 & \\
\hline « 30 bedridden days with suffering & 11.2 & 5.9 & 8.1 & 13.5 & 17.9 & \\
\hline $\begin{array}{l}\geq 30 \text { bedridden days with no } \\
\text { suffering }\end{array}$ & 6.2 & 1.5 & 3.5 & 6.4 & 14.1 & \\
\hline$\geq 30$ bedridden days with suffering & 7.4 & 2.7 & 4.7 & 7.2 & 15.7 & \\
\hline \multicolumn{7}{|l|}{ Age group (years): } \\
\hline $65-79$ & 35.9 & 63.5 & 46.3 & 21.7 & 8.9 & \multirow{4}{*}{$0 \dagger$} \\
\hline $80-89$ & 31.4 & 25.1 & 34.9 & 37.3 & 28.3 & \\
\hline $90-99$ & 23.4 & 9.5 & 14.9 & 30.1 & 40.0 & \\
\hline$\geq 100$ & 9.4 & 1.9 & 4.0 & 10.9 & 22.8 & \\
\hline \multicolumn{7}{|l|}{ Ethnicity: } \\
\hline Minority group & 5.5 & 7.3 & 5.3 & 5.0 & 4.1 & \multirow{2}{*}{0.001} \\
\hline Han & 94.5 & 92.7 & 94.7 & 95.0 & 95.9 & \\
\hline \multicolumn{7}{|l|}{ Residence: } \\
\hline Urban & 43.5 & 44.4 & 42.3 & 42.8 & 44.5 & \multirow{2}{*}{0.549} \\
\hline Rural & 56.5 & 55.6 & 57.7 & 57.2 & 55.5 & \\
\hline \multicolumn{7}{|l|}{ Years of schooling: } \\
\hline 0 & 34.9 & 24.8 & 32.8 & 39.2 & 43.4 & \multirow{2}{*}{0} \\
\hline$\geq 1$ & 65.1 & 75.2 & 67.2 & 60.8 & 56.6 & \\
\hline \multicolumn{7}{|l|}{ White collar occupation: } \\
\hline No & 85.1 & 82.0 & 83.5 & 87.2 & 88.3 & \multirow{2}{*}{0} \\
\hline Yes & 14.9 & 18.0 & 16.5 & 12.8 & 11.7 & \\
\hline \multicolumn{7}{|l|}{ Economic independence: } \\
\hline No & 59.2 & 46,6 & 51.8 & 66.3 & 73.9 & \multirow{2}{*}{0} \\
\hline Yes & 40.8 & 53.4 & 48.2 & 33.7 & 26.1 & \\
\hline \multicolumn{7}{|l|}{ Good family economic status: } \\
\hline No & 81.4 & 79.2 & 78.7 & 82.4 & 85.7 & \multirow{2}{*}{0} \\
\hline Yes & 18.6 & 20.8 & 21.3 & 17.6 & 14.3 & \\
\hline \multicolumn{7}{|l|}{ Adequate medication: } \\
\hline No & 9.5 & 4.6 & 7.2 & 9.4 & 17.7 & \\
\hline Yes & 90.5 & 95.4 & 92.8 & 90.6 & 82.3 & 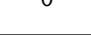 \\
\hline Married: & & & & & & \\
\hline No & 53.3 & 37.1 & 46.1 & 61.8 & 69.5 & \\
\hline Yes & 46.7 & 62.9 & 53.9 & 38.2 & 30.5 & 0 \\
\hline Close proximity to children: & & & & & & \\
\hline No & 18.4 & 17.3 & 17.0 & 19.3 & 20.1 & \\
\hline Yes & 81.6 & 82.7 & 83.0 & 80.7 & 79.9 & 0.014 \\
\hline Religious involvement: & & & & & & \\
\hline No & 88.3 & 85.2 & 87.1 & 88.0 & 93.4 & \\
\hline Yes & 11.7 & 14.8 & 12.9 & 12.0 & 6.6 & 0 \\
\hline Regular exercise: & & & & & & \\
\hline No & 59.3 & 48.5 & 51.1 & 57.0 & 82.7 & \\
\hline Yes & 40.7 & 51.5 & 48.9 & 43.0 & 17.3 & 0 \\
\hline Smoked in past five years: & & & & & & \\
\hline No & 56.7 & 51.5 & 51.8 & 58.8 & 65.6 & \\
\hline Yes & 43.3 & 48.5 & 48.2 & 41.1 & 34.4 & 0 \\
\hline
\end{tabular}

*Measured in 2005.

†Based on standard Pearson $\mathrm{x}^{2}$ two sided test; all other $\mathrm{P}$ values were based on Kendall's $\mathrm{T}$ test.

$\ddagger$ Measured between 2002 and 2005 . 
available on request). Each item was assigned a value of 1 in the presence of a deficit (otherwise 0), and a value of 2 was assigned for people with two or more serious conditions that led to admission to hospital or a period of confinement in bed. ${ }^{13}$ We then constructed a frailty index by summarising all deficits and dividing by the total number of possible deficits.

Although studies have shown that a frailty index does not require the same number or type of items to estimate accurate proportions of frailty levels, ${ }^{38}$ the items comprising our index are similar to those used in studies from Canada, ${ }^{15}$ the United States,${ }^{8}$ and Hong Kong. ${ }^{13}$ We tested the validity and sensitivity of the frailty index by analysing several indices on the basis of differing combinations of variables. These results showed that as long as we included variables characterising each of the major domains of health (activities of daily living, instrumental activities of daily living, chronic illnesses, and cognitive functioning), the pattern of frailty with age remained consistent. In the Chinese longitudinal healthy longevity survey, levels of frailty increased exponentially from ages 65 to 100 and then levelled off (results not shown); therefore we split the frailty index into fourths for men and for women to account for non-linear relations between levels of frailty and type of death.

To obtain robust estimates we also adjusted analyses for several previously identified confounding factors. ${ }^{40}$ Various coding strategies were assessed for each
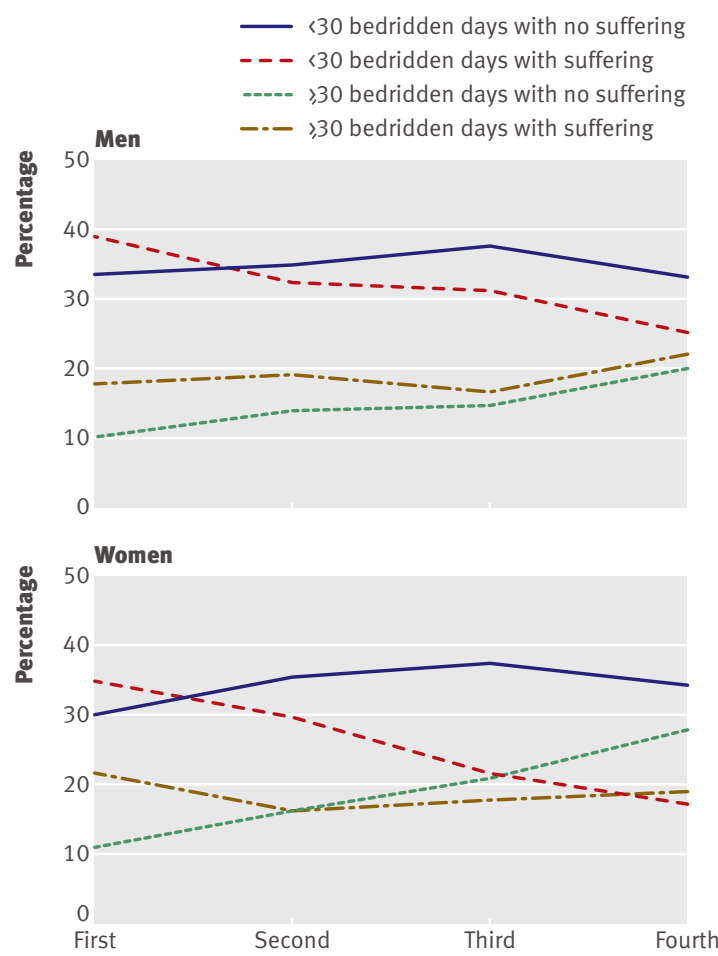

Frailty index (fourths)

Fig 2 Observed proportion of type of death among the deceased sample by frailty and sex in 2002 and 2005 waves of Chinese longitudinal healthy longevity survey measure and the results were similar; therefore, we dichotomised all of the confounding variables (except age). Measures of demographic background included age categorisations of 65-79 (reference group), 80-89, 90-99, and 100 and older, people from non-Han ethnic minorities, and those living in urban areas. Measures of socioeconomic status included education (any formal education), primary lifetime occupation as a white collar worker, economic independence (primary financial source from own work or pension), family in good economic standing (self rated as rich compared with other families in the community), and being in receipt of adequate drugs for any illnesses. Social contact and support measures included current marital status, close proximity to children (coresiding with biological or adopted children, including a spouse's child, or having one or more biological children living in the same village or street block), and religious activity almost every day or sometimes. Measures for health practices included exercising on a regular basis and having ever smoked in the past five years.

\section{Statistical analysis}

We computed sample distributions of the study variables separately by sex and level of frailty. To test differences in the distributions of frailty for dichotomous variables we used Kendall's $\tau$ tests and for categorical variables Pearson's $\chi^{2}$ tests. Multinomial logistic regression models were used to estimate the relative risk ratios and 95\% confidence intervals associated with levels of frailty and the four types of death. We used two sets of nested regression models to adjust for the confounding risk factors. The first set of analyses tested the effects of frailty by sex while adjusting for basic personal information (age, ethnicity, and urban residence). In the second set of analyses we included the additional confounding variables for socioeconomic status, social contact and support, and health practices. We then computed the predicted proportions of the types of death (among decedents) across age and frailty for men and for women.

All analyses were done using Stata version 10.1. Overall, few data were missing for study variables $(<4 \%)$, and we used multiple imputation methods to correct for missing values on the individual measures. ${ }^{41}$ Research shows that including variables related to sample selection produces unbiased estimates in the absence of weights ${ }^{42}$ and our preliminary analyses showed that the pattern of findings was consistent with those based on weighted data. Therefore we did not use weighted data in the regression analyses.

\section{RESULTS}

Tables 1 and 2 present the sample distributions of the study variables by sex and level of frailty. Among those in the lowest fourth (least frail) for frailty, $84.9 \%$ of men and $86.1 \%$ of women survived to 2005 compared with just over $25 \%$ of men and women in the highest fourth (most frail) for frailty. Among decedents, about 25\% of men and women had fewer than 30 bedridden days before death, although women were less likely than 
Table 2 |Characteristics of women in 2002 wave of Chinese longitudinal healthy longevity survey by level of frailty. Values are percentages of participants unless stated otherwise

\begin{tabular}{|c|c|c|c|c|c|c|}
\hline \multirow[b]{2}{*}{ Variables } & \multirow[b]{2}{*}{ Total } & \multicolumn{4}{|c|}{ Frailty index (fourths) } & \multirow[b]{2}{*}{$P$ value } \\
\hline & & 1st (least frail) & 2nd & $3 r d$ & 4th (most frail) & \\
\hline No of participants & 7813 & 1981 & 1901 & 2074 & 1857 & \\
\hline Survivors* & 56.0 & 86.1 & 68.2 & 45.4 & 25.5 & \multirow{6}{*}{$0 \dagger$} \\
\hline \multicolumn{6}{|l|}{ Type of death‡: } & \\
\hline $\begin{array}{l}\text { «30 bedridden days with no } \\
\text { suffering }\end{array}$ & 15.7 & 4.2 & 11.3 & 20.6 & 25.4 & \\
\hline « 30 bedridden days with suffering & 10.1 & 4.9 & 9.6 & 12.2 & 13.5 & \\
\hline $\begin{array}{l}\geq 30 \text { bedridden days with no } \\
\text { suffering }\end{array}$ & 10.0 & 1.7 & 5.5 & 11.7 & 21.1 & \\
\hline$\geq 30$ bedridden days with suffering & 8.3 & 3.1 & 5.4 & 10.1 & 14.5 & \\
\hline \multicolumn{7}{|l|}{ Age group(years): } \\
\hline $65-79$ & 26.7 & 62.8 & 28.6 & 8.4 & 3.7 & \multirow{4}{*}{$0 \dagger$} \\
\hline $80-89$ & 23.4 & 24.4 & 31.9 & 21.6 & 16.9 & \\
\hline $90-99$ & 24.0 & 9.1 & 24.2 & 32.7 & 31.2 & \\
\hline$\geq 100$ & 25.9 & 3.6 & 15.4 & 37.3 & 48.2 & \\
\hline \multicolumn{7}{|l|}{ Ethnicity: } \\
\hline Minority group & 6.4 & 8.0 & 7.2 & 5.6 & 4.6 & \multirow{2}{*}{0.001} \\
\hline Han & 93.6 & 92.0 & 92.8 & 94.4 & 95.4 & \\
\hline \multicolumn{7}{|l|}{ Residence: } \\
\hline Urban & 43.1 & 43.5 & 41.0 & 43.8 & 43.9 & \multirow{2}{*}{0.777} \\
\hline Rural & 56.9 & 56.5 & 59.0 & 56.2 & 56.1 & \\
\hline \multicolumn{7}{|l|}{ Years of schooling: } \\
\hline 0 & 83.2 & 73.9 & 83.3 & 87.4 & 87.7 & \multirow{2}{*}{0} \\
\hline$\geq 1$ & 16.8 & 26.1 & 16.7 & 12.6 & 12.3 & \\
\hline \multicolumn{7}{|l|}{ White collar occupation: } \\
\hline No & 97.1 & 95.3 & 96.9 & 98.0 & 98.2 & \multirow{2}{*}{0} \\
\hline Yes & 2.9 & 4.7 & 3.1 & 2.0 & 1.8 & \\
\hline \multicolumn{7}{|l|}{ Economic independence: } \\
\hline No & 87.4 & 73.1 & 86.6 & 93.6 & 96.0 & \multirow{2}{*}{0} \\
\hline Yes & 12.6 & 26.9 & 13.4 & 6.4 & 4.0 & \\
\hline \multicolumn{7}{|l|}{ Good family economic status: } \\
\hline No & 84.0 & 81.2 & 82.9 & 85.1 & 87.7 & \multirow{2}{*}{0} \\
\hline Yes & 16.0 & 19.8 & 17.1 & 14.9 & 12.3 & \\
\hline \multicolumn{7}{|l|}{ Adequate medication: } \\
\hline No & 13.1 & 6.6 & 11.3 & 14.2 & 20.0 & \\
\hline Yes & 86.9 & 93.4 & 88.7 & 85.8 & 80.0 & 0 \\
\hline Married: & & & & & & \\
\hline No & 83.7 & 63.1 & 81.5 & 93.4 & 96.0 & \\
\hline Yes & 16.3 & 36.9 & 18.5 & 6.6 & 4.0 & 0 \\
\hline Close proximity to children: & & & & & & \\
\hline No & 15.7 & 13.5 & 15.0 & 17.0 & 17.1 & \\
\hline Yes & 84.3 & 86.5 & 85.0 & 83.0 & 82.9 & 0.010 \\
\hline Religious involvement: & & & & & & \\
\hline No & 79.1 & 70.5 & 73.1 & 83.0 & 89.4 & \\
\hline Yes & 20.9 & 29.5 & 26.9 & 17.0 & 10.6 & 0 \\
\hline Regular exercise: & & & & & & \\
\hline No & 75.7 & 60.5 & 68.3 & 80.5 & 93.3 & \\
\hline Yes & 24.3 & 39.5 & 31.7 & 19.5 & 6.7 & 0 \\
\hline Smoked in past five years: & & & & & & \\
\hline No & 90.3 & 89.4 & 90.5 & 90.1 & 91.4 & \\
\hline Yes & 9.7 & 10.6 & 9.5 & 9.9 & 8.6 & 0.033 \\
\hline
\end{tabular}

*Measured in 2005.

†Based on standard Pearson $\mathrm{x}^{2}$ two sided test; all other $\mathrm{P}$ values were based on Kendall's $\mathrm{T}$ test.

$\ddagger$ Measured between 2002 and 2005 . 
men to suffer before death. A greater proportion of women than men had 30 or more bedridden days either with or without suffering before death. Those with the most frailty had the highest rates for all types of death. Men with the most frailty were more likely to suffer before death $(17.9 \%$ with $<30$ bedridden days, and $15.7 \%$ with $\geq 30$ bedridden days) compared with women, who were more likely to experience no suffering before death $(25.4 \%$ with $<30$ bedridden days, and $21.1 \%$ with $\geq 30$ bedridden days), especially after at least 30 bedridden days.

Although men had a slightly younger age distribution (and death rates) than women, both sexes exhibited commensurate increases in age across levels of frailty. Similar proportions of men and women were from ethnic minority groups (about $6 \%$ ) and lived in urban areas (about 43\%); however, men and women from ethnic minority groups were less frail than those of Han ethnicity. There was no trivariate difference between sex, frailty, and urban residence. At nearly all levels of frailty men had higher socioeconomic status, were more likely to be married, took regular exercise, and had smoked in the past five years compared with women. Women were more likely to live close to their children and engage in religious activities compared with men. For both sexes, socioeconomic status, social contacts and support, and exercise declined across levels of frailty. Conversely, the proportion of participants who smoked was lower for men and women with higher levels of frailty.

For both sexes the proportion of participants who did not suffer before death increased with age and the proportion who suffered decreased with age (figs 1 and 2). Across levels of frailty, the most pronounced patterns were the precipitous declines in the numbers of participants who experienced fewer than 30 bedridden days with suffering and increases in the number of participants who experienced 30 or more bedridden days with no suffering, particularly among women. Consistent with tables 1 and 2 , the plotted probabilities also indicated that women were more likely to experience no suffering before death compared with men.

Table 3 presents the results from the multinomial analyses for the associations between frailty and type of death for men and women. The relative risk ratios for model 1 are adjusted for age, ethnicity, and urban residence and for model 2 are further adjusted for several confounding variables. Overall, increased frailty was associated with higher risks of death, regardless of type, and was especially pronounced for those with high levels of frailty. Adjusting for differences in socioeconomic status, social contact or support, and health

Table 3 | Relative risk ratios from multinomial logistic regression models of type of death by sex and frailty of participants in Chinese longitudinal healthy longevity survey

\begin{tabular}{|c|c|c|c|c|}
\hline \multirow[b]{2}{*}{ Variables } & \multicolumn{2}{|c|}{ Men } & \multicolumn{2}{|c|}{ Women } \\
\hline & $\begin{array}{l}\text { Model } 1 * \text { : relative risk } \\
\text { ratio }(95 \% \mathrm{Cl})\end{array}$ & $\begin{array}{l}\text { Model } 2 \dagger \text { : relative risk } \\
\text { ratio }(95 \% \mathrm{Cl})\end{array}$ & $\begin{array}{l}\text { Model 1*: relative risk } \\
\text { ratio }(95 \% \mathrm{Cl})\end{array}$ & $\begin{array}{l}\text { Model } 2 \dagger \text { : relative risk } \\
\text { ratio }(95 \% \mathrm{Cl})\end{array}$ \\
\hline \multicolumn{5}{|c|}{$\ll 30$ bedridden days with no suffering $v$ survival } \\
\hline \multicolumn{5}{|l|}{ Frailty index fourth: } \\
\hline First (least frail) & 1.00 (reference) & 1.00 (reference) & 1.00 (reference) & 1.00 (reference) \\
\hline Second & $1.21(0.90$ to 1.64$)$ & 1.19 (0.88 to 1.62$)$ & 1.83 (1.40 to 2.39$)$ & 1.77 (1.35 to 2.32$)$ \\
\hline Third & $1.90(1.48$ to 2.44$)$ & $1.87(1.45$ to 2.41$)$ & $2.98(2.26$ to 3.94$)$ & 2.81 (2.12 to 3.73$)$ \\
\hline Fourth (most frail) & $4.02(3.44$ to 6.43$)$ & $4.16(3.16$ to 5.47$)$ & $5.67(4.29$ to 7.49$)$ & 5.28 (3.95 to 7.06$)$ \\
\hline \multicolumn{5}{|c|}{$<30$ bedridden days with suffering $v$ survival } \\
\hline \multicolumn{5}{|l|}{ Frailty index fourth: } \\
\hline First & 1.00 (reference) & 1.00 (reference) & 1.00 (reference) & 1.00 (reference) \\
\hline Second & $1.14(0.84$ to 1.54$)$ & $1.11(0.82$ to 1.50$)$ & 1.85 (1.43 to 2.40$)$ & 1.77 (1.37 to 2.30$)$ \\
\hline Third & $1.96(1.53$ to 2.51$)$ & $1.82(1.41$ to 2.34$)$ & $2.19(1.65$ to 2.91$)$ & $2.02(1.52$ to 2.68$)$ \\
\hline Fourth & $4.42(3.43$ to 5.70$)$ & 3.87 (1.96 to 3.32$)$ & $4.27(3.22$ to 5.65$)$ & $3.87(2.90$ to 5.16$)$ \\
\hline \multicolumn{5}{|c|}{$\geq 30$ bedridden days with no suffering $v$ survival } \\
\hline \multicolumn{5}{|l|}{ Frailty index fourth: } \\
\hline First & 1.00 (reference) & 1.00 (reference) & 1.00 (reference) & 1.00 (reference) \\
\hline Second & $1.47(0.93$ to 2.36$)$ & $1.45(0.90$ to 2.31$)$ & 2.13 (1.44 to 3.17$)$ & $2.06(1.39$ to 3.06$)$ \\
\hline Third & $2.32(1.57$ to 3.41$)$ & $2.20(1.49$ to 3.24$)$ & $4.29(2.90$ to 6.35$)$ & $4.00(2.68$ to 5.96$)$ \\
\hline Fourth & $7.61(5.21$ to 11.13$)$ & 6.67 (4.51 to 9.85$)$ & $11.53(7.84$ to 16.96$)$ & $10.53(7.06$ to 15.70$)$ \\
\hline \multicolumn{5}{|c|}{$\geq 30$ bedridden days with suffering $v$ survival } \\
\hline \multicolumn{5}{|l|}{ Frailty index fourth: } \\
\hline First & 1.00 (reference) & 1.00 (reference) & 1.00 (reference) & 1.00 (reference) \\
\hline Second & 1.62 (1.10 to 2.39$)$ & 1.58 (1.07 to 2.33$)$ & $1.69(1.22$ to 2.35$)$ & 1.61 (1.16 to 2.24$)$ \\
\hline Third & $2.36(1.70$ to 3.27$)$ & 2.23 (1.60 to 3.09$)$ & $2.97(2.10$ to 4.19$)$ & 2.66 (1.87 to 3.76$)$ \\
\hline Fourth & $8.70(6.31$ to 12.00$)$ & 7.75 (5.54 to 10.83$)$ & $6.98(5.00$ to 9.75$)$ & $5.96(4.23$ to 8.39$)$ \\
\hline
\end{tabular}

*Adjusted for age, ethnicity, and urban residence.

†Adjusted for age, ethnicity, urban residence, socioeconomic status, social contact and support, and health practices. 
Table 4 |Predicted proportions* of type of death among deceased men in Chinese longitudinal healthy longevity survey by age and frailty

\begin{tabular}{lcccc} 
& \multicolumn{4}{c}{ Type of death } \\
\cline { 2 - 5 } Variables & $\begin{array}{c}\text { (30 bedridden } \\
\text { days, no suffering }\end{array}$ & $\begin{array}{c}\text { \&30 bedridden } \\
\text { days, suffering }\end{array}$ & $\begin{array}{c}\geq 30 \text { bedridden } \\
\text { days, no suffering }\end{array}$ & $\begin{array}{c}\geq 30 \text { bedridden } \\
\text { days, suffering }\end{array}$ \\
$\begin{array}{l}\text { Age } \geq 65 \text {, all frailty } \\
\text { fourths }\end{array}$ & 34.7 & 29.5 & 16.3 & 19.5 \\
\hline Age $\geq 65$ & & & & \\
\hline Frailty fourth: & 38.2 & 33.6 & 13.3 & 15.0 \\
\hline First (least frail) & 36.1 & 29.8 & 15.1 & 19.0 \\
\hline Second & 35.8 & 31.9 & 14.7 & 17.6 \\
\hline Third & 30.2 & 27.5 & 17.1 & 25.2 \\
\hline Fourth (most frail) & & &
\end{tabular}

\section{Age 65-79}

Frailty fourth:

\begin{tabular}{lcccc}
\hline First & 22.3 & 44.0 & 9.4 & 24.3 \\
\hline Second & 21.0 & 38.2 & 10.7 & 30.1 \\
\hline Third & 21.2 & 40.7 & 10.5 & 27.6 \\
\hline Fourth & 18.0 & 33.1 & 12.2 & 36.6 \\
\hline
\end{tabular}

Age 80-89

Frailty fourth:

\begin{tabular}{lllll}
\hline First & 31.0 & 40.6 & 11.6 & 16.8 \\
\hline Second & 29.6 & 35.8 & 13.4 & 21.1 \\
\hline Third & 29.8 & 37.8 & 13.1 & 19.2 \\
\hline Fourth & 26.1 & 31.8 & 15.7 & 26.4 \\
\hline
\end{tabular}

Age 90-99

Frailty fourth:

\begin{tabular}{lllll}
\hline First & 44.5 & 28.7 & 14.5 & 12.3 \\
\hline Second & 42.4 & 25.4 & 16.7 & 15.5 \\
\hline Third & 42.7 & 26.8 & 16.4 & 14.1 \\
\hline Fourth & 37.8 & 22.8 & 19.8 & 19.6 \\
\hline
\end{tabular}

Age $\geq 100$

Frailty fourth:

\begin{tabular}{lllll}
\hline First & 49.2 & 23.5 & 16.4 & 10.9 \\
\hline Second & 46.8 & 20.7 & 18.8 & 13.7 \\
\hline Third & 47.2 & 21.9 & 18.5 & 12.5 \\
\hline Fourth & 41.8 & 18.6 & 22.3 & 17.3 \\
\hline
\end{tabular}

*Adjusted for age, ethnicity, urban residence, socioeconomic status, social contact and support, and health practices.
5.7 times (95\% confidence interval 4.3 to 7.5$)$ and 11.5 times $(7.8$ to 17.0$)$ more likely to experience no suffering before death compared with survival, respectively. The corresponding rates among men were 4.0 (3.4 to 6.4 ) and 7.6 (5.2 to 11.1). Alternatively, the relative risks for experiencing fewer than 30 bedridden days or 30 or more bedridden days with suffering among men with the most frailty were 4.4 (3.4 to 5.7 ) and 8.7 (6.3 to 12.0) among men with the most frailty and 4.30 (3.2 to 5.6) and 7.00 (5.0 to 9.8) among women with the most frailty. Thus the observed sex differences in the proportions of death (figs 1 and 2) were supported in the multivariate relative risk models.

Tables 4 and 5 present the predicted proportions of the types of death by age, frailty, and sex from table 3 (model 2). Overall, the most common type of death for men and women in the Chinese longitudinal healthy longevity survey was characterised by 30 or fewer bedridden days with no suffering. Given the same level of frailty and adjusting for confounders, the proportion of men who experienced suffering and 30 or more bedridden days before death was greater than the proportion of men bedridden with no suffering before death; however, the opposite was found among women. Analyses further indicated that the oldest men and women ( $\geq 90$ years) were more likely to experience fewer bedridden days with no suffering before death than their younger counterparts. The results also showed that fewer than 30 bedridden days with no suffering before death were more common than 30 or more bedridden days with no suffering, whereas fewer than 30 bedridden days with suffering were more common than 30 or more bedridden days with suffering for each sex and age group. Moreover, being bedridden for fewer than 30 days or for 30 or more days with suffering was less prevalent with increasing age compared with being bedridden for fewer than 30 days or 30 or more days with no suffering, which was especially apparent for the most frail participants.

Higher levels of frailty among men were associated with greater proportions of death with 30 or more bedridden days and with lesser proportions of death with fewer than 30 bedridden days for every age group. Among women, being bedridden for fewer than 30 days with suffering decreased and being bedridden for 30 or more days with no suffering increased across all levels of frailty within each age group; however, differences were modest for experiencing fewer than 30 bedridden days with no suffering and 30 or more bedridden days with suffering across levels of frailty.

\section{DISCUSSION}

Results based on a prospective cohort of adults aged 65 to 109 in China showed that higher levels of frailty increased the risk of experiencing all four types of death that we examined: being bedridden for fewer than 30 days with or with no suffering or being bedridden for 30 or more days with or with no suffering. People with greater frailty were more likely to experience a greater number of bedridden days before death than those with less frailty. The increasing effects of 
frailty on suffering were primarily limited to those who experienced 30 or more bedridden days before death. The association between frailty and type of death differed by sex and age, and adjusting for differences in socioeconomic status, social support, and health practices had almost no impact on the relations. Overall, the results provided strong evidence that cumulative deficits, quantified with a frailty index, influenced not only the likelihood of dying but also the quality of life before death. ${ }^{1543}$

Overall, compared with men, women exhibited higher risks of experiencing one of the four types of death as levels of frailty increased, owing to their older age and therefore increased physiological frailty. Evidence from Western nations and China concur that older women are often in poorer health yet live longer than men. ${ }^{445}$ The implications of this finding are perhaps more pronounced in developing countries such as

Table 5 |Predicted proportions* of type of death among deceased women in Chinese longitudinal healthy longevity survey by age and frailty

\begin{tabular}{lcccc} 
& \multicolumn{3}{c}{ Type of death } \\
\cline { 2 - 5 } Variables & $\begin{array}{c}\text { \&0 bedridden } \\
\text { days, no suffering }\end{array}$ & $\begin{array}{c}\text { \&30 bedridden } \\
\text { days, suffering }\end{array}$ & $\begin{array}{c}\geq 30 \text { bedridden } \\
\text { days, no suffering }\end{array}$ & $\begin{array}{c}\geq 30 \text { bedridden } \\
\text { days, suffering }\end{array}$ \\
$\begin{array}{l}\text { Age } \geq 65, \text { all frailty } \\
\text { fourths }\end{array}$ & 35.3 & 23.0 & 22.7 & 19.0 \\
\hline Age $\geq 65$ & & & & \\
\hline Frailty fourth: & 36.6 & 28.9 & 15.1 & 19.4 \\
\hline First (least frail) & 35.9 & 29.1 & 17.2 & 17.8 \\
\hline Second & 37.0 & 22.0 & 21.6 & 19.4 \\
\hline Third & 32.2 & 20.5 & 26.3 & 21.0 \\
\hline Fourth (most frail) & & & & \\
\hline Age $65-79$ & & & & \\
\hline
\end{tabular}

Age 65-79

Frailty fourth:

\begin{tabular}{lllll}
\hline First & 22.3 & 40.7 & 7.9 & 29.2 \\
\hline Second & 22.6 & 41.2 & 9.3 & 26.9 \\
\hline Third & 24.8 & 32.3 & 12.4 & 30.5 \\
\hline Fourth & 22.2 & 29.6 & 15.6 & 32.6 \\
\hline
\end{tabular}

Age 80-89

Frailty fourth:

\begin{tabular}{lllll}
\hline First & 28.8 & 37.2 & 13.9 & 20.1 \\
\hline Second & 28.7 & 37.1 & 16.1 & 18.2 \\
\hline Third & 30.6 & 28.3 & 20.9 & 20.1 \\
\hline Fourth & 27.2 & 25.6 & 26.0 & 21.2 \\
\hline
\end{tabular}

\section{Age 90-99}

Frailty fourth:

\begin{tabular}{lllll}
\hline First & 38.3 & 26.2 & 15.7 & 19.8 \\
\hline Second & 38.0 & 26.0 & 18.2 & 17.9 \\
\hline Third & 39.1 & 19.2 & 22.7 & 19.0 \\
\hline Fourth & 34.6 & 17.3 & 28.1 & 20.0 \\
\hline
\end{tabular}

Age $\geq 100$

Frailty fourth:

\begin{tabular}{lllll} 
First & 41.6 & 24.9 & 16.3 & 17.2 \\
\hline Second & 41.1 & 24.7 & 18.8 & 15.5 \\
\hline Third & 42.1 & 18.1 & 23.4 & 16.4 \\
\hline Fourth & 37.3 & 16.4 & 29.0 & 17.3 \\
\hline
\end{tabular}

*Adjusted for age, ethnicity, urban residence, socioeconomic status, social contact and support, and health practices.
China. In many cases, Chinese women bear a disproportionate amount of the care giving to spouses and their respective parents. These women also have the fewest economic and familial resources and exhibit the most frailty as they age. Future research should investigate ways to reduce the excess risks of dying related to frailty by minimising the causes and consequences of declining physiological reserves, particularly among women. Despite these disadvantages our results showed that for men the risks increased most noticeably for deaths with suffering, whereas for women the risks increased much more for every level of frailty for deaths with no suffering. This is consistent with studies from the West. ${ }^{4647}$ Research suggests that elderly women are less likely to afford or use life sustaining treatments and instead rely on care from hospices $^{48-50}$ and alternative modes of emotional and spiritual care during the dying process, ${ }^{51}$ which may minimise the degree of subjective suffering.

That extremely old men and women in our study ( $\geq 90$ years) were less likely to suffer before death supports research from younger samples in hospice and clinical settings in North America. ${ }^{47} 52$ The lack of suffering among extremely old people may be due to the precipitous withdrawal of life sustaining treatments, ${ }^{53}$ that such people are psychologically or genetically robust and less likely to express pain or discomfort, ${ }^{5455}$ or that because participants and their families had sufficient time to prepare for death their perception of suffering might have been overlooked or expected. ${ }^{56}$ These speculations are, however, cautious and we encourage research to verify our results. Nonetheless, it seems that subjective assessments of the quality of death at the upper limits of age share a common expectation and convey a universal respect for longevity regardless of the population or culture.

\section{Strengths and limitations of the study}

A major strength of this research is the application of a comprehensive measure of frailty in a large scale prospective sample. The results showed that the frailty index had a significant impact on the type of death experienced by older adults and underscored a critical aspect of the quality of dying that is often overlooked in cohort studies. The current findings add to an increasing body of evidence showing that frailty indices are valid indicators for quantifying ageing and predicting mortality. ${ }^{155758}$ For example, research has shown a significant correlation between frailty index levels and the time to death in the absence of a relation between chronological age and time to death. ${ }^{14}$ Research has also shown that a frailty index correlated with death better than did chronological age, especially within short intervals (for example, $<4$ years). ${ }^{8}$ Another recent study showed that a cumulative deficits approach (frailty index) was more effective than a phenotypic approach in predicting susceptibility to death. ${ }^{39}$ Our sensitivity analyses closely replicated age-sex distributions in frailty indices in other studies. ${ }^{14} 1539$ On the basis of this evidence we are confident about the validity of our frailty measure. 


\section{WHAT IS ALREADY KNOWN ON THIS TOPIC}

An index for frailty is a valid construct for measuring mortality and the use of healthcare services

\section{WHAT THIS STUDY ADDS}

The frailty index was strongly associated with suffering and the amount of time spent bedridden before death

Extremely old people ( $\geq 90$ years) were most likely to experience 30 or fewer bedridden days with no suffering before death compared with other old adults

Women with the highest levels of frailty were most likely to experience 30 or more bedridden days with no suffering before death

Nevertheless, several limitations of this study warrant further attention. Although we made great efforts to validate the frailty index, we encourage research to develop and test other quantifications of frailty. Undoubtedly as our understanding of physiological pathways increases, we expect future studies to continue to refine measures of frailty and extend the current research, which assumes equal item weight and excludes important indicators of immune function and biomarkers. ${ }^{38}$

Another limitation is that our longitudinal measures of the types of death include only two domains of the quality of dying previously identified in the literature. ${ }^{2159}$ Although the qualitative assessment of suffering before death is a key dimension of quality of death, the measure of suffering in the Chinese longitudinal healthy longevity survey was ascertained from the decedents' next of kin and may be biased. This is because some research shows that proxy reports are not always consistent with reports by individuals before their death. ${ }^{60}$ Nonetheless, future studies should examine other assessments of suffering before dying as well as different sources and subjective dimensions of the types of death faced by older adults. ${ }^{36} \mathrm{~A}$ final concern is that sample attrition from 2002 to 2005 was not random and may have introduced bias in our estimates. However, supplementary analyses indicated that the general patterns and conclusions of our analysis did not change regardless of whether we parameterised the lost sample as a categorical outcome or imputed the missing cases.

\section{Clinical and policy implications}

Despite these limitations our results provide a broader understanding of the association between frailty and quality of death and may have implications for clinicians, individuals, and public health. In medical settings, curative treatments are often eclipsed in moderate to extreme cases of frailty by palliative care in efforts to reduce discomfort and enhance the quality of life before death. The clinical application of a checklist (or index) for frailty can be a useful diagnostic tool that helps to characterise a patient's biological age compared with their chronological age, although unlike the phenotypic approach the frailty index may need translation in clinical practice for specific treatments. ${ }^{389}$ Accordingly, implementing such measures may improve a doctor's repertoire for determining appropriate treatments and perhaps intervening at preclinical stages of frailty or before phenotypic criteria are detectable, especially for extremely old adults. ${ }^{3961}$

From an individual's standpoint it is also imperative to identify the manifestations and levels of frailty to specialise end of life care, minimise suffering, and promote a peaceful death. Our findings suggest that the medical care of older adults should be tailored to the age specific and sex specific levels of frailty that were shown to influence one's susceptibility to preventable suffering before dying. For example, low levels of frailty due to functional decline could be targeted with appropriate exercise regimens that also prevent or delay the onset of additional frailty from other latent and treatable deficits (for example, cognitive decline). In other words, health practitioners should utilise the generality of a frailty index while recognising the individual differences in cumulative deficits and the changing dynamics of health and care in late ages. ${ }^{6263}$

Our findings have potential implications for improving China's public healthcare system. China is the world's largest developing country and is currently facing unique challenges to its healthcare system as an unbalanced population structure and a rapidly ageing population is straining the traditional family oriented system of care. We believe that the present study is an important step towards identifying frailty and its association with the quality of death in a rapidly developing nation. However, more research is needed to address how medical expenditures and facilities can be best utilised for patients at the end of their life and to reduce the escalating burden of frailty for family care givers in the context of China's unique healthcare structure. We hope that our findings facilitate more discussion and analysis of effective measures for end of life care and the advancement of community based care resources that are largely undeveloped in China.

Contributors: MED and DG contributed equally and are listed as the first and corresponding author. Both of them conceived and designed the study and drafted and revised the manuscript. DG prepared the data and did the analyses, had full access to the data, and is guarantor. DFW and ZY revised the manuscript.

Funding: The data used in this study were from the 2002 and 2005 waves of the Chinese longitudinal healthy longevity survey which was funded by the National Institute on Aging, the China Natural Science Foundation, the China Social Science Foundation, the United Nations Population Funds, and the Hong Kong Research Grant Council. DG's work was partly supported by a National Institute of Aging grant (R01 AG023627, PI: ZY) when he was at Duke University and was partly supported by a provost mini-grant for internationalisation at Portland State University. The work by MED and DFW was partially supported by the Carolina Population Center at the University of North Carolina at Chapel Hill postdoctoral training programme, funded by the National Institute of Child Health and Human Development grant NIH 5-T32HD07168-28 (MED) and National Institute on Aging grant T32 AG00155 (DFW). ZY's work was supported by NIA grant R01 AG023627. Competing interests: None declared.

Ethical approval: This study was approved by the institutional review board of Duke University health system institutional review board.

1 Bortz WM. A conceptual framework of frailty: a review. J Gerontol A Biol Sci Med Sci 2002;57A:M283-8.

2 Rockwood K, Fox RA, Stolee P, Robertson D, Beattie BL. Frailty in elderly people: an evolving concept. Can Med Assoc J 1994;150:489-95. 
3 Markle-Reid M. Conceptualizations of frailty in relation to older adults. J Adv Nurs 2003;44:58-68.

4 Campbell AJ, Buchner DM. Unstable disability and the fluctuations of frailty. Age Ageing 1997;26:315-8.

5 Fried LP, Tangen CM, Walston J, Newman AB, Hirsch C, Gottdiener J, et al. Frailty in older adults: evidence for a phenotype. J Gerontol $A$ Biol Sci Med Sci 2001;56A:M146-57.

6 Rockwood K, Mogilner A, Mitnitski A. Changes with age in the distribution of a frailty index. Mech Ageing Dev 2004;125:517-9.

7 Cohen $\mathrm{HJ}$. In searching of the underlying mechanisms of frailty. J Gerontol A Biol Sci Med Sci 2000;55A:M706-8.

8 Kulminski A, Yashin A, Arbeev K, Akushevich I, Ukraintseva S, Land K, et al. Cumulative index of health disorders as an indicator of agingassociated processes in the elderly: results from analyses of the national long term care survey. Mech Ageing Dev 2007:250-8.

9 Mitnitski AB, Mogilner AJ, Rockwood K. Accumulation of deficits as a proxy measure of aging. Scientific World 2001;1:323-6.

10 Morley JE, Perry HM III, Miller DK. Something about frailty. J Gerontol A Biol Sci Med Sci 2002;57A:M698-704.

11 Morley JE, Haren NT, Rolland Y, Kim MJ. Frailty. Med Clin North Am 2006;90:837-47

12 Walston J, Hadley EC, Ferrucci L,Guralnik JM, Newman AB, Studenski SA, et al. Research agenda for frailty in older adults: towards a better understanding of physiology and etiology: summary from the American Geriatrics Society/National Institute on Aging Research Conference on frailty in old adults. I Am Geriatr Soc 2006;54:991-1001.

13 Goggins WB, Woo J, Sham A, Ho SC. Frailty index as a measure of biological age in a Chinese population. J Gerontol A Biol Sci Med Sci 2005;60A:M1046-51.

14 Mitnitski A, Graham JE, Mogilner AJ, Rockwood K. Frailty, fitness and late-life mortality in relation to chronological and biological age. $B M C$ Geriatr 2002;2:1

15 Mitnitski A, Song X, Skoog I, Broe GA, Cox JL, Grunfeld E, et al. Relative fitness and frailty of elderly men and women in developed countries and their relationship with mortality. I Am Geriatr Soc 2005;35:2184-9.

16 Puts MT, Lips P, Deeg DJ. Sex differences in the risk of frailty for mortality independent of disability and chronic diseases. I Am Geriatr Soc 2005; 53:40-7.

17 Rockwood K. Frailty and its definitions: a worthy challenge. J Am Geriatr Soc 2005;53:1069-70.

18 Song X, Mitnitski A, MacKnight C, Rockwood K. Assessment of individual risk of death using self-report data: an artificial neural network compared with a frailty index. J Am Geriatr Soc 2004;52:1180-4.

19 Janssen I, Shepard DS, Katzmarzyk PT, Roubenoff R. The healthcare costs of sarcopenia in the United State. J Am Geriatr Soc 2004;52:80-5.

20 Field MJ, Cassell CK, eds. Approaching death: improving care at the end of life. Washington DC: National Academic Press, 1997.

21 Patrick DL, Curtis JR, Engelberg RA, Nielsen E, McCown E. Measuring and improving the quality of dying and death. Ann Intern Med 2003;139:410-5

22 Wong PTP. Meaning in life and meaning in death in successful aging. In: Tomer A, ed. Death attitudes and the older adult: theories concepts and applications. Philadelphia, PA: Brunner-Routledge, 2000.

23 Curtis JR, Rubenfeld GD, eds. Managing death in the intensive care unit. New York: Oxford University Press, 2001.

24 Gruenewald DA, White EJ. The illness experience of old adults near the end of life: a systematic review. Anesthesiology Clin N Am 2006;24:163-80.

25 Patrick DL, Engelberg RA, Curtis JR. Evaluating the quality of dying and death. J Pain Symptom Manage 2001;22:717-26.

26 Seale C, van der Geest S. Good and bad death: introduction. Soc Sci Med 2004;58:883-5.

27 Steward AL, Teno J, Patrick DL, Lynn J. The concept of quality of life of dying persons in the context of health care. J Pain Symptom Manage 1999; 17:93-108.

28 Foley KM. Pain and symptom control in the dying ICU patient. In: Curtis JR, Rubenfeld GD, eds. Managing death in the intensive care unit. New York: Oxford University Press, 2001:103-25.

29 Emanuel EJ. Cost savings at the end of life. What do the data show? JAMA 1996;275:1907-14.

30 United Nations. World population prospects: the 2006 revision. 2007. http://esa.un.org/unpp/.

31 Gu D, Dupre ME, Liu G. Characteristics of the institutionalized and community-residing oldest-old in China. Soc Sci Med 2007;64:871-83.

32 Gu D. General data assessment of the Chinese longitudinal healthy longevity survey in 2002. In: Zeng Y, Poston D, Smith J, Vlosky DA Gu D, eds. Healthy longevity in China: demographic, socioeconomic, and psychological dimensions. Dordrecht, Netherlands: Springer, 2008:39-59.
33 Gu D, Dupre ME. Assessment of reliability of mortality and morbidity in the 1998-2002 CLHLS waves. In: Zeng Y, Poston D, Smith J, Vlosky DA, Gu D, eds. Healthy longevity in China: demographic, socioeconomic, and psychological dimensions. Dordrecht, Netherlands: Springer, 2008:99-115.

34 Zeng Y, Gu D. Reliability of age reporting among the Chinese oldestold in the CLHLS data sets. In: Zeng Y, Poston D, Smith J, Vlosky DA Gu D, eds. Healthy longevity in China: demographic, socioeconomic and psychological dimensions. Dordrecht, Netherlands: Springer, 2008:61-78

35 George LK. Research design in end-of-life research: state of science. Gerontologist 2002;42(special issue III):86-98

36 Hickman SE, Tilden VP, Tolle SW. Family reports of dying patients distress: the adaptation of a research tool to assess global symptom distress in the last week of life. J Pain Symptom Manage 2001;22:565-74.

37 Yashin Al, Arbeev KG, Kulminski A, Akushevich I, Akushevich L, Ukraintseva SV. Cumulative index of elderly disorders and its dynamic contribution to mortality and longevity. Rejuv Res 2007;10:75-86.

38 Rockwood K, Andrew M, Mtinitski A. A comparison of two approaches to measuring frailty in elderly people. / Gerontol A Biol Sci Med Sci 2007:62A:738-43.

39 Kulminski A, Ukraintseva S, Kulminskaya IV, Arbeev K, Land KC, Yashin A. Cumulative deficits better characterize susceptibility to death in elderly people than phenotypic frailty: lessons from the Cardiovascular Health Study. J Am Geriatr Soc 2008;56:898-903.

40 Ferrucci L, Turchi A, Fumagallo S, Di Bari M, Silerstrini G, Zacchei S, et al. Sex-related differences in the length of disability prior to death in older persons. Aging Clin Exp Res 2003;15:310-4.

41 Allison P. Missing data. Thousand Oaks, California: Sage, 2002.

42 Winship C, Radbill L. Sampling rates and regression analysis. Sociol Methods Res 1994;23:230-57.

43 Pronovost P, Angus DG. Economics of managing death in the ICU. In: Curtis JR, Rubenfeld GD, eds. Managing death in the intensive care unit. New York: Oxford University Press, 2001:245-55.

44 Robine JM, Jagger C, Mathers CD, Crimmins EM, Suzman RM, eds Determining health expectancies. New York: Wiley, 2003.

45 Dupre ME, Liu G, Gu D. Predictors of longevity: evidence from the oldest-old in China. Am J Public Health 2008;98:1203-8.

46 Bookwala J, Coppola KM, Fagerlin A, Ditto PH, Danks JH, Smucker WD. Gender differences in older adults' preferences for lifesustaining medical treatments and end-of-life values. Death Studies 2001;25:127-49.

47 Cohen LW, Germain MJ, Poppel DM, Woods AL, Pekow PS, Kjellstrand CM. Dying well after discontinuing the life-support treatment of dialysis. Arch Intern Med 2000;160:2513-8.

48 Goodlin SJ, Zhong Z, Lynn J, Teno JM, Fago JP, Desbiens N, et al. Factors associated with use of cardiopulmonary resuscitation in seriously ill hospitalized adults. JAMA 1999;282:2333-9.

49 Hauser RM, Roan CL. The class of 1957 in their mid-60s: a first look. Working paper No 2006-03. Madison, WI: Center for Demography and Ecology, University of Wisconsin-Madison.

50 Iwashyna TJ, Chang VW, Zhang JX, Christakies NA. The lack of effect of market structure on hospice use. Health Serv Res 2002;37:1531-51.

51 Idler EL, KasI SV, Hays IC. Patterns of religious practice and belief in the last year of life. J Gerontol B Psychol Sci Soc Sci 2001;36B:S326-34.

52 Abraham A, Kutner IS, Beaty B. Suffering at the end of life in the setting of low physical symptom distress. J Palliat Med 2006;9:658-65

53 Hamel MB, Teno IM, Goldman L, Lynn J, Davis RB, Galanos AN, et al. Patient age and decisions to withhold life-sustaining treatments from seriously ill, hospitalized adults. Ann Intern Med 1999;130:116-25.

54 Willcox DC, Willcox BJ, Hsueh WC, Suzuki M. Genetic determinants of exceptional human longevity: insights from the Okinawa Centenarians Study. Age 2006;28:313-32.

55 Martin P, Poon LW, Kim E, Johnson MA. Social and psychological resources in the oldest old. Exp Aging Res 1996;22:121-39.

56 Pinquart $M$, Sorensen S. Preparation for death and preparation for care in older community-dwelling adults. Omega 2002;45:69-88.

57 Bergman H, Ferrucci L, Guralnik J, Hogan DB, Hummel S, Karunananthan S, et al. Frailty: an emerging research and clinical paradigm-issues and controversies. J Gerontol A Biol Sci Med Sci 2007;62:731-7.

58 Abellan Van Kan G, Rolland Y, Berhman H, Morley JE, Kritchevsky SB, Vellas B. The I.A.N.A. task force on frailty assessment of older people in clinical practice. / Nutr Health Aging 2008;12:29-37.

59 Steinhauser KS, Clipp EC, Tulsky JA. Evolution in measuring the quality of dying. J Palliat Med 2002;5:407-14.

60 Hinton J. How reliable are relatives' retrospective reports of terminal illness? Patients and relatives' accounts compared. Soc Sci Med 1996;43:1229-36. 
61 Martin FC, Brighton P. Frailty: different tools for different purposes? Age Aging 2008;37:129-31.

62 Gill TM, Robison JT, Tinetti ME. Predictors of recovery in activities of daily living among disabled older persons living in the community. J Gen Intern Med 1997;12:757-62.
63 Gu D, Zeng Y. Sociodemographic effects on the onset and recovery of ADL disability among Chinese oldest-old. Demogr Res 2004;11:1-42.

Accepted: 11 December 2008 